\title{
REAL-TIME TRACKING OF PRODUCTION CONTROL: REQUIREMENTS AND SOLUTIONS
}

\author{
Hylton Olivieri ${ }^{1}$, Olli Seppänen ${ }^{2}$, and Antti Peltokorpi ${ }^{3}$
}

\begin{abstract}
Production control in construction has been mainly discussed within the scope of Lean Construction, through tools and methods such as Last Planner System (LPS), Location-Based Management System (LBMS), and Takt Time Planning (TTP). However, despite the increasing use of these systems, information about the use of equipment, labour, and materials is still gathered through manual data collection, if at all. Real-time process information about these production factors is missing.

This paper proposes an intelligent system for real-time production control (iCONS), which has been developed based on the requirements set by construction professionals from four countries, the existing technical solutions that have been used in real-time tracking, and on the proposed new solutions that can fulfill the requirements. Four types of requirements were identified based on interviews: 1) safety management, 2) monitoring process information, productivity and waste, 3) material logistics, and 4) location-based information on pull basis. The proposed system fills the key requirements by sharing and integrating real-time information between materials tracked with RFID tags, labour and equipment tracked by Bluetooth beacons, communicating with location-based gateways and iCONS app through a cloud-based solution. Project teams can use this system to improve production efficiency, management of suppliers, and safety conditions.
\end{abstract}

Keywords: Lean construction, production control, tracking, resources, communication systems.

\section{INTRODUCTION}

Production control in construction has been mainly discussed within the scope of Lean Construction. Among others, its tools and methods include: 1) the Last Planner System (LPS, Ballard 2000) which focuses on the social process of planning and reliable commitments; 2) the Location-Based Management System (LBMS, Kenley and Seppänen 2010), which includes a technical system and a process for better planning and control using locations and; 3) Takt Time Planning (TTP, e.g., Frandson et al. 2013) which is a related planning and controlling approach using fixed durations for each location. Various combined approaches have also been proposed. For example, the combination of LPS and LBMS was proposed by Seppänen et al. (2010). Although good results of LBMS have been reported in literature (e.g., Seppänen et al. 2014), contractors are complaining about the difficulty of manual data collection (e.g., Cruz Rios et al. 2015). Furthermore, all of the production control approaches rely heavily on social processes and manual data collection (Pradhananga and Teizer 2013). For example, the LPS is typically implemented with

1 Postdoctoral Researcher, Department of Civil Engineering, Aalto University School of Engineering, Espoo, Finland, hylton.olivieri@aalto.fi

2 Professor of Practice, Department of Civil Engineering, Aalto University School of Engineering, Espoo, Finland, olli.seppanen@aalto.fi

3 Assistant Professor, Department of Civil Engineering, Aalto University School of Engineering, Espoo, Finland, antti.peltokorpi@aalto.fi 
manual techniques, such as using post-it notes to plan collaboratively in a phase scheduling meeting (e.g., Tsao and Hammons 2014). Recent approaches include mobile applications, which distribute the plan to the workers and allow them to use mobile devices to report progress (Dave et al. 2014). LBMS has been implemented in software (currently Vico Schedule Planner) but progress tracking remains manual using control charts (Kenley and Seppänen 2010). TTP is a different scheduling methodology but in software terms has been typically implemented with Vico Schedule Planner as well (Frandson et al. 2013). Each approach relies on manual collection of information through discussions or spreadsheets, requiring substantial amounts of human labour to collect and analyse data, which eventually was prone to human error (Costin et al. 2012), besides it is an expensive, inaccurate and inefficient process (Jiang et al. 2012).

Construction sites are usually characterized by a complex set of interactions between space, equipment, labour, materials, and final product (Golovina et al. 2016). Moving resources efficiently on site, and between projects, requires good coordination of activities and specialized information systems (Vasenev et al. 2014), resulting in an accurate process information. With the current manual approaches, it can be said that the full potential of production control have not been achieved.

Technology has been developed to the point where it is possible to configure a system for a truly intelligent construction site, where all resources can be tagged and located in real-time (e.g., Cheng and Teizer 2013; Jiang et al. 2015). Mobile technology enables real -time communication with workers (e.g., Dave et al. 2014) and building information modelling (BIM) provides context for decision-making. However, although improving construction productivity through integration and automation, it is essential to identify the processes where technologies may be implemented in a cost effective manner (Grau et al. 2009). Despite the increasing use of BIM and production planning technologies, realtime information about the production factors, equipment, labour, and materials, is still gathered through manual practices, if at all.

The aim of this paper is to propose an intelligent construction site system for real-time production control, named iCONS. The system will be part of an international research project managed by Aalto University and supported by construction companies, software companies, operators, and international universities from four countries: Finland, USA, Brazil and China. iCONS will be developed based on the main requirements of the companies, the existing technical solutions that have been used in real-time tracking, and new developed solutions that can address any gaps. In this paper, a literature review was carried out to identify existing tracking solutions and the use of real-time data in construction management. After that, an interview study among building practitioners was conducted to evaluate the main requirements of real-time production control. Finally, a lean real-time production control system is proposed.

\section{BACKGROUND}

A lean production control system must consider resource flows, continuity of work for resources, reducing cycle time, forecasting based on actual progress and eliminating waste. In relation to resources, Koskela (1999) defined seven types of flows (or preconditions) for a construction task: 1) design information, 2) components and materials, 3) labour, 4) equipment, 5) space, 6) connecting works, and 7) external conditions. If there is a problem with any of these flows, making-do waste will result (Koskela 2004). iCONS and real-time production control could help particularly with materials, labour, equipment and space 
flows. Real-time information about the status of these flows could enable better production management and less waste in the process.

Tracking material resources and their respective locations, implies two sets of requirements: 1 ) determining the location when materials are delivered to a construction site and; 2) once delivered, tracking the location of materials with enough accuracy (Song et al. 2006). Different manufacturing environments may define product delivery strategies, such as Make-to-stock (MTS), Assemble-to-order (ATO), Make-to-order (MTO) and Engineer-to-order (ETO) (Olhager 2003). Each one of these requires a different real-time tracking mechanism. For example, ETO products have elaborate supply chains and a long process from design to installation. It is a challenging task to efficiently identify, track and locate these components through a construction supply chain as the process is usually monitored manually by using paper-based methods. Manual material tracking methods result in problems such as late deliveries, missing components and inefficient assembly, reflecting in additional labour and material costs (Demiralp et al. 2012). In this paper, we are focusing on materials and components including both off-site and on-site logistics. Although the main use case will be tracking ETO products, the system should be able to handle also other types of important materials.

Tracking of labour is an important issue to keep production flowing. In addition, the quantity of labour hours spent completing tasks represent a large portion of costs in a project (Costin et al. 2012). Thus, maximizing labour productivity is an important factor affecting both costs and production. However, labour consumption tracking has been a challenging problem, involving multiple human behavioural and qualitative factors (Jiang et al. 2015). Trying to solve this problem, real-time tracking may be used on identifying critical personnel and activities instantly, increasing the flow of project information and control actions (Cordova and Brilakis 2008). This information could be used to drive LBMS technical calculations (Kenley and Seppänen 2010), highlighting problems in real-time rather than based on weekly manual input. In addition, real-time tracking could help on identifying typical construction wastes, such as unnecessary movements, poor logistics conditions, and making-do (Koskela 2004).

It is widely known that construction jobsites are hazardous environments due to the continuous and dynamic interactions between various entities, such as heavy equipment and workers on foot (Wang and Razavi 2015; Golovina et al. 2016). On a worksite, it is important that construction workers and equipment operators can recognize each other in real-time (Golovina et al. 2016). Considering the high number of contact accidents and the severity of the consequences, potential collisions should be prevented in a timely manner (Wang and Razavi 2015). Despite the development of recent solutions, such as sending alarms based on the proximity of workers and equipment (Wang and Razavi 2015; Park et al. 2016), or the integrated use of BIM to pro-actively improve construction safety, there is a lack of studies on remote monitoring for improving safety and health of the construction workforce (Cheng et al. 2013).

Despite improvements in remote data sensing and intelligent data processing systems, few data on visualization tools are used in a virtual reality environment in real-time (Cheng and Teizer 2013). For example, Dave et al. (2014) proposed a solution integrating video-cameras and magnetic boards on monitoring tasks progress. However, this solution requires manual insertion of data on the boards. Thus, there is a clear disconnection among real-time information, resource flows and locations, representing an opportunity for developing a lean real-time production control system. 


\section{METHOD}

First, a literature review was conducted, aiming to investigate the existing solutions of real-time production control. After that, face-to-face interviews with building professionals were done, aiming to investigate: 1) the main challenges of real-time production control; 2) the expected benefits on implementing an intelligent system, using real-data; 3) the most demanding and interesting use cases and; 4) the possible integration of Building Information Modelling (BIM) and an intelligent production control system. A standard list of ten questions was prepared and seven interviews (one with each end-user partner) were done in three countries (Brazil, China and USA). Additionally, a focus group interview with all Finnish partners was conducted in Finland. Based on the findings of the interviews and focus group, four most relevant requirement themes were found. Then, an intelligent system was proposed, considering requirements, existing solutions, and solutions to be developed and tested in future research.

\section{FINDINGS}

\subsection{Interviews}

The interviewed companies highlighted the following themes as the most relevant requirements of real-time production control:

- Safety management: highlighting work in hazardous areas and risks related to interactions between equipment and labour; safety aspect is also critical to provide value for workers so that they can accept to be tracked.

- Process information, productivity and waste: tracking movements of the workers on construction site, and controlling how much time workers spend in one location, analysing productivity rates and waste of time, analysing what has been completed in each location, linking images automatically to locations.

- Material logistics: controlling the logistics of off-site and on-site materials.

- Location-based information on pull basis: giving information to superintendents and foremen in real-time based on the location they are in.

\subsection{Proposed real-time production control system}

To address the requirements, an intelligent construction site (iCONS) scheme is proposed, as shown in Figure 1. The central idea of this system is real-time tracking of production factors, where an app will integrate several technological tracking solutions and provides real-time information for decision-makers. The app, installed on smartphones devices of the project team, will receive real-time information of materials, through reading RFID tags or via wireless (Link 1). The position of mobile resources, such as workers and equipment, will be determined through the interaction between beacons and gateways, which are installed in distinct locations (Link 2). The app determines the location of the foreman / superintendent by accessing the same gateways (Link 3). A data storage cloud system will receive online information from the gateways (Link 4), automatically updating data on the app (Link 5). The app is used to update production status based on locationbased suggestions and to link pictures and notes to the location (Links 3 and 5). When the plan is known and workers who have spent time in the location are known, it is possible to ask targeted questions about what scope was completed and to document the completed 
work in a picture linked to the location. Table 1 shows a sample of existing solutions found and proposed links and solutions, aiming to cover the requirements.

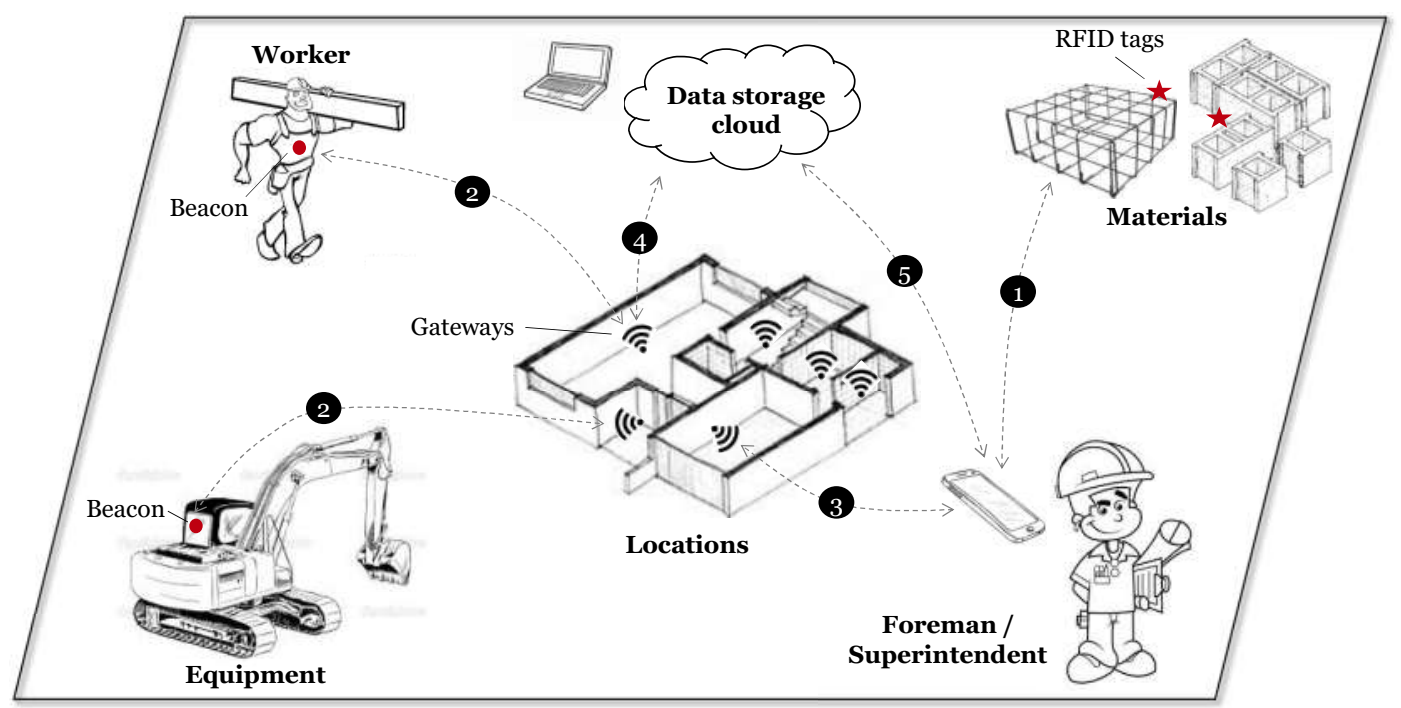

Figure 1: iCONS system

Key: Link 1) Interaction between RFID tag materials and iCONS app; Link 2)

Interaction between beacons sensors and gateways; Link 3) Interaction between iCONS app and gateways; Link 4) Interaction between gateways and data storage cloud; Link 5) Interaction between iCONS app and data storage cloud.

\section{DISCUSSION}

The great novelty of the iCONS system is not related to the proposed individual links because each has been previously explored individually, but the interactions among them in a common platform, connected through a data storage cloud and an app, providing realtime information to the project team (summarized in Table 1).

Existing solutions in safety control have been providing enough information of behaviour of workers (Cheng et al. 2013), hazardous areas, and the interaction between workers and equipment (Golovina et al. 2016). However, locations, equipment and workers have not been integrated. The integrated use of beacons and gateways, which are installed in strategic locations, combined with previous BIM simulations and analysis, may facilitate the identification of hazardous areas, sending alarms where and when necessary. Furthermore, risks can be mitigated through the combination of BIM simulations and realtime resources tracking.

Currently, the actuals work in place (scope), production rates and quantities are not automatically gathered. However, technologies such as photogrammetry and laser scanning can be considered to fulfil this gap, generating real-time information for Last Planners to make comparisons with the plan.

Traditionally, labour on construction sites has been tracked with good accuracy (Montaser and Moselhi 2014). However, it has been very difficult to know what the workers have been working on and in which locations they have spent time (Jiang et al. 2015). Process information has not been commonly connected with real-time status; in addition, productivity is still measured through manual practices (Pradhananga and Teizer 
2013). With the implementation of iCONS, real-time control may be provided through the integration of location, workers and the app, via data storage cloud, where the project team would receive online information about labour productivity and to compare the status of each location to the project schedule or weekly commitments. iCONS will also provide opportunities for analysing wasted time in real-time, alarming the management of problems and making waste visible to the team. The goal is to make information cycle more agile, improving the efficiency of the crews and fixing errors faster than when using manual controls. Furthermore, this process will help to automate production control, once it is possible to get real-time status information with a high level of accuracy.

Table 1: Requirements, existing and proposed solutions

\begin{tabular}{|c|c|c|}
\hline Requirements & Samples of existing solutions & Proposed links and solutions \\
\hline $\begin{array}{c}\text { Safety } \\
\text { management }\end{array}$ & $\begin{array}{l}\text { Monitoring safe and unsafe } \\
\text { behaviour (Cheng et al. 2013); } \\
\text { Proximity detection and alert } \\
\text { system using beacons (Park et al. } \\
\text { 2016); GPS on identifying and } \\
\text { analysing hazardous areas } \\
\text { (Golovina et al. 2016); }\end{array}$ & $\begin{array}{l}\text { Link } 2 . \text { Beacons positioned in } \\
\text { equipment and workers will interact } \\
\text { with gateways, detecting and } \\
\text { alarming potential risks in hazardous } \\
\text { areas, which will be previously } \\
\text { identified through BIM model; }\end{array}$ \\
\hline $\begin{array}{l}\text { Process } \\
\text { information, } \\
\text { productivity and } \\
\text { waste }\end{array}$ & $\begin{array}{l}\text { Tracking labour through video } \\
\text { cameras (Cordova and Brilakis } \\
\text { 2008) or websites, computers, } \\
\text { tablets and smartphones (Jiang et } \\
\text { al. 2015); Triangulation and } \\
\text { proximity to identify the location } \\
\text { of the workers (Montaser and } \\
\text { Moselhi 2014); }\end{array}$ & $\begin{array}{l}\text { Links } 3,4 \text { and } 5 \text {. Real-time } \\
\text { information will be provided through } \\
\text { the interaction between data storage } \\
\text { cloud and app. The project team will } \\
\text { be able to analyse productivity of } \\
\text { subcontractors, comparing the status } \\
\text { with the schedule and identifying the } \\
\text { wasting time; }\end{array}$ \\
\hline $\begin{array}{l}\text { Material } \\
\text { logistics }\end{array}$ & $\begin{array}{l}\text { RFID systems (Demiralp et al. } \\
\text { 2012); RFID integrated with } \\
\text { mobile devices and web portals } \\
\text { (Wang 2008); }\end{array}$ & $\begin{array}{l}\text { Link } 1 . \text { RFID tags will provide } \\
\text { accurate information of materials } \\
\text { manufacturing status, quantities } \\
\text { needed and delivered, and location; }\end{array}$ \\
\hline $\begin{array}{l}\text { Location-based } \\
\text { information on } \\
\text { pull basis }\end{array}$ & $\begin{array}{l}\text { Real-time positioning sensors } \\
\text { (Cheng and Teizer 2013); UWB } \\
\text { system (Cheng et al. 2011); }\end{array}$ & $\begin{array}{c}\text { Links 2, } 3 \text { and } 4 \text {. Locations identified } \\
\text { through gateways. Location } \\
\text { information such as time spent, the } \\
\text { planned schedule, required quantities, } \\
\text { quality checks etc., will be provided in } \\
\text { real-time }\end{array}$ \\
\hline
\end{tabular}

RFIDs tags have been applied for tracking materials (Demiralp et al. 2012). Through the integration of materials status with locations, internal and external logistics process may be facilitated, and delivery locations can be prioritized in accordance with the project schedule. The supply chain process can be automatically updated. Thus, manufacturing, delivery and internal storage will be integrated with the needs of every location.

Real-time position sensors (Cheng and Teizer 2013) and recent systems (Cheng et al. 2011) have been applied for indicating the location of resources relatively accurately. However, this real-time information is not integrated with labour productivity in locations. Thus, real-time and accurate information could improve production control, helping on rescheduling process, defining control actions and prioritising activities. 
Real-time information would support production control, and help reducing waste, particularly that related to flows of material, labor, equipment and space. For example, the real-time tracking of locations and production rates will improve the analysis of overproduction. The tracking of labor and movement will improve the analysis of waiting time.

\section{CONCLUSIONS}

The iCONS system proposes the integration of several technological solutions to form a lean production control system supporting LPS, LBMS or takt-time planning, providing real-time information to the project teams and potentially improving the production control process. The proposed system fills the key requirements gathered in interviews of building professionals in four countries. Project teams can use this system to improve production efficiency, management of suppliers, and safety conditions. The iCONS system is under development and its benefits will be validated in future research.

\section{REFERENCES}

Ballard, G. (2000). The Last Planner System of Production Control. Thesis (Doctor of Philosophy), University of Birmingham.

Cheng, T., Venugopal, M., Teizer, J., and Vela, P.A. (2011). Performance Evaluation of Ultra Wideband Technology for Construction Resource Location Tracking in Harsh Environments. Automation in Construction, 20, pp. 1173-1184.

Cheng, T., and Teizer, J. (2013). Real-time Resource Location Data Collection and Visualization Technology for Construction Safety and Activity Monitoring Applications. Automation in Construction, 34, pp. 3-15.

Cheng, T., Migliaccio, G.C., Teizer, J., and Gatti, U.C. (2013). Data Fusion of Real-time Location Sensing and Physiological Status Monitoring for Ergonomics Analysis of Construction Workers. ASCE Journal of Computing in Civil Engineering, 27(3), 10.1061/(ASCE)CP.1943-5487.0000222, pp. 320-335.

Cordova, F., and Brilakis, I. (2008). On-site 3D Vision Tracking of Construction Personnel. Proc. 16th Ann. Conf. of the Int'l Group for Lean Construction. Manchester, UK.

Costin, A., Pradhananga, N., and Teizer, J. (2012). Leveraging Passive RFID Technology for Construction Resource Field Mobility and Status Monitoring in a High-rise Renovation Project. Automation in Construction, 24, pp. 1-15.

Cruz Rios, F., Grau, D., Assainar, R., Ganapaty, R., and Diosdado, J. (2015). Stabilizing Craft Labor Workflow with Instantaneous Progress Reporting. Proc. 23th Ann. Conf. of the Int'l Group for Lean Construction. Perth, Australia.

Dave, B., Kubler, S., Främling, K., and Koskela, L. (2014). Addressing Information Flow in Lean Production Management and Control in Construction. Proc. 22th Ann. Conf. of the Int'l Group for Lean Construction. Oslo, Norway

Demiralp, G., Guven, G., and Ergen, E. (2012). Analyzing the Benefits of RFID Technology for Cost Sharing in Construction Supply Chains: A Case Study on Prefabricated Precast Components. Automation in Construction, 24, pp. 120-129.

Frandson, A., Berghede, K., and Tommelein, I.D. (2013). Takt Time Planning for Construction of Exterior Cladding. Proc. 21th Ann. Conf. of the Int'l Group for Lean Construction. Fortaleza, Brazil. 
Golovina, O., Teizer, J., and Pradhananga, N. (2016). Heat Map Generation for Predictive Safety Planning: Preventing Struck-by and Near Miss Interactions between Workerson-foot and Construction Equipment. Automation in Construction, 71, pp. 99-115.

Grau, D., Caldas, C.H., Haas, C.T., Goodrum, P.M., and Gong, J. (2009). Assessing the Impact of Materials Tracking Technologies on Construction Craft Productivity. Automation in Construction, 18, pp. 903-911.

Jiang, S., Jang, W.S., and Skibniewski, M.J. (2012). Selection of Wireless Technology for Tracking Construction Materials Using a Fuzzy Decision Model. Journal of Civil Eng. and Manage., 18(1), pp. 43-59.

Jiang, H., Lin, P., Qiang, M., and Fan, Q. (2015). A Labor Consumption Measurement System Based on Real-time Tracking Technology for Dam Construction Site. Automation in Construction, 52, pp. 1-15.

Kenley, R., and Seppänen, O. (2010). Location-Based Management for Construction: Planning, Scheduling and Control. Spon Press, London and New York.

Koskela, L. (1999). Management of Production in Construction: A Theoretical View. Proc. 7th Ann. Conf. of the Int'l Group for Lean Construction. Berkeley, California.

Koskela, L. (2004). Making-do - The eighth category of waste. Proc. 12th Ann. Conf. of the Int'l Group for Lean Construction. Helsingor, Denmark.

Montaser, A., and Moselhi, O. (2014). RFID Indoor Location Identification for Construction Projects. Automation in Construction, 39, pp. 167-179.

Olhager, J. (2003). Strategic Positioning of the Order Penetration Point. International Journal of Production Economics, 85, pp. 319-329.

Park, J.P., Marks, E., Cho, Y.K., and Suryanto, W. (2016). Performance Test of Wireless Technologies for Personnel and Equipment Proximity Sensing in Work Zones. ASCE Journal of Constr. Eng. Manage., 142(1), 10.1061/(ASCE)CO.1943-7862.0001031.

Pradhananga, N., and Teizer, J. (2013). Automatic Spatio-temporal Analysis of Construction Site Equipment Operations Using GPS Data. Automation in Construction, 29, pp. 107-122.

Seppänen, O., Ballard, G., and Pesonen, S. (2010). The Combination of Last Planner System and Location-Based Management System. Lean Construction Journal, pp. 44-54.

Seppänen, O., Evinger, J., and Mouflard, M. (2014). Effects of the Location-Based Management System on Production Rates and Productivity. Construction Management and Economics, 32(6), pp. 608-624.

Song, J., Haas, C.T., and Caldas, C.H. (2006). Tracking the Location of Materials on Construction Job Sites. ASCE Journal of Constr. Eng. and Manage., 132(9), 10.1061/(ASCE)0733-9364(2006)132:9(911), pp. 911-918.

Tsao, C., and Hammons, G. (2014). Learning to See Simplicity within a Complex Project through the Lens of Pull Planning. Proc. 22th Ann. Conf. of the Int'l Group for Lean Construction. Oslo, Norway.

Vasenev, A., Hartmann, T., and Dorée, A.G. (2014). A Distributed Data Collection and Management Framework for Tracking Construction Operations. Advanced Engineering Informatics, 28, pp. 127-137.

Wang, L.C. (2008). Enhancing Construction Quality Inspection and Management Using RFID Technology. Automation in Construction, 17, pp. 467-479.

Wang, J., and Razavi, S.N. (2015). Low False Alarm Rate Model for Unsafe-Proximity Detection in Construction. ASCE Journal of Computing in Civil Engineering, 30(2), 10.1061/(ASCE)CP.1943-5487.0000470, 04015005. 